\title{
Üretim İşletmelerinin Endüstri 4.0 Entegrasyonunun Veri Zarflama Analizi ile Değerlendirilmesi
}

\author{
Adem ERÍK ${ }^{1}$, Yusuf KUVVETLi ${ }^{* 1}$ \\ ${ }^{1}$ Çukurova Üniversitesi, Mühendislik Fakültesi, Endüstri Mühendisliği Bölümü, Adana
}

Geliş tarihi: 25.04.2021 Kabul tarihi: 13.09.2021

$\ddot{O} z$

İnternetin, sistemlerin fiziksel ve siber entegrasyonuyla dönüşümü dördüncü sanayi devrimi olarak anılan Endüstri 4.0 (I4.0) kavramını ortaya çıkarmıştır. Birçok teknolojinin bir araya gelmesi bulut teknolojisi, dijitalleşme, büyük veri ve nesnelerin interneti gibi kavramlar ile yeni bir üretim modeli oluşmaktadır. I4.0 tabanlı bir üretim modeline geçmek isteyen bir işletme için önemli bir süreç ve teknoloji hazırlığ ve altyapı ihtiyacı oluşmaktadır. Bu nedenle, işletmeler dönüşüm için öncelikle bu modeli içeren yönetim şekli, süreç ve teknolojilerine olan uyumu sağlamak zorundadır. Bu çalışmada, farklı üretim firmalarında gerçekleştirilen yüz yüze görüşmeler sonucunda elde edilen verilerle işletmelerin I4.0 entegrasyon yeteneği analiz edilmiş̧ir. Veriler, veri zarflama analizi ile değerlendirilmiş ve işletmelerin I4.0 uyum yeteneği göreceli olarak saptanmıştır. İşletmeler değerlendirilirken bilgi teknolojileri, araştırma-geliştirme faaliyetleri, müşteri ilişkileri, finansman, kalite yönetimi, planlama, maliyet yönetimi vb. birçok farklı başılı altında analiz edilerek detaylı bir değerlendirme yapılması sağlanmıştır. Yapılan değerlendirme sonucunda incelenen 24 imalat işletmesinin 13 'ü dönüşüm için etkin olduğu sonucuna ulaşılmıştır.

Anahtar Kelimeler: Endüstri 4.0, Endüstri 4.0 Entegrasyonu, Veri zarflama analizi, Üretim yönetimi

\section{Evaluation of Industry 4.0 Integration of Manufacturing Enterprises with Data Envelopment Analysis}

\begin{abstract}
The internet and the transformation of physical and cyber systems' integration have created Industry 4.0 (I4.0), referred to as the fourth industrial revolution. Combining many technologies forms a new production model with concepts such as cloud technology, digitalization, big data, and the internet of things. A necessary process and technology preparation, and infrastructure need arise for an enterprise that wants to switch to an I4.0-based production model. For this reason, businesses must first ensure compliance with the management style, processes, and technologies that include this model for transformation. In this study, the I4.0 integration capability of the enterprises was analyzed with the data obtained from face-to-face interviews conducted in different manufacturing companies. The data were evaluated with the Data Envelopment Analysis technique, and the I4.0 compliance capability of the enterprises was determined relatively. A detailed evaluation has been achieved by analyzing various
\end{abstract}

*Sorumlu yazar (Corresponding author): Yusuf KUVVETLİ, ykuvvetli@cu.edu.tr 
aspects such as information technologies, R\&D activities, customer relations, financing, quality management, planning, and cost management. As a result of the evaluation, it was concluded that 13 of the 24 manufacturing enterprises examined were effective for transformation.

Keywords: Industry 4.0, Industry 4.0 Integration, Data envelopment analysis, Production management

\section{GíRiş}

Ürün ve hizmet ortaya koyan işletmeler arasında var olan rekabet dijitalleşme, siber fiziksel sistemler, büyük veri, nesnelerin interneti vb. I4.0 kavramlarının etkisini göstermesi ile farklı bir eksene taşınmaya hazırlanmaktadır. İlk olarak Almanya'da açıklanan I4.0, akıllı fabrikalar kurmak için siber fiziksel sistemler, nesnelerin interneti (IoT), bulut bilişim gibi üretim teknolojilerin geliştirilmesi ve dönüştürülmesi olarak tanımlanmaktadır [1]. Artan rekabet özellikle üretim işletmelerini üretim alışkanlıklarını ve teknolojisini değiştirmeye zorlamaktadır. I4.0 teknolojileri ile işletmelere dijital çözümler sunarken şirketlerin sunulan çözümleri nasıl kullandığı ile ilgili bir anlayış mevcut değildir [2].

I4.0 üretim sistem teknolojilerini akıllı üretim süreçleri ile birleştirerek iş modelleri ve üretim değer zincirleri için yeni bir teknolojik çağ olarak görülmektedir. $\mathrm{Bu}$ çă̆ ile tedarik zincirleri bütünleşik olarak birden çok sektörde küçük, orta ve büyük ölçekli şirketlerdeki fiziksel süreçlerin ve bilgi akışların gerektiği yerde ve zamanda kullanılması sağlanmaktadır [3]. Tüm bu sistem ile sağlanan akıllı üretim, cihazların veya makinelerin geçmiş deneyimlere ve öğrenme kapasitelerine dayalı olarak farklı durumlara ve gereksinimlere göre davranışlarını değiştirmesini sağlamak için belirli temel teknolojiler gerektirir [4].

Akıllı üretimi gerçekleştirmek için gereken teknolojiler, üretim sistemlerine entegre edilerek doğrudan iletişim sağlayan ve zamanında problemlerin çözülmesi ve uyarlanabilir kararların alınmasına olanak tanır. Bazı teknolojiler buna ek olarak gerçek zamanlı, akıllı ve her yerde bulunan endüstriyel uygulamaları hayata geçirmek için deneyimlerden yararlanan yapay zekaya (YZ) sahiptir [5]. Tüm bu nedenlerden dolayı I4.0 çözümleri yapı bakımından güçlü teknolojik altyap1 gerektirmektedir. $\mathrm{Bu}$ anlamda, I4.0 entegrasyonunu sağlamak isteyen işletmelerin bilişim ve üretim teknolojilerini geliştirmeleri gerekmektedir.

$\mathrm{Bu}$ makalede, Adana çevresinde faaliyet gösteren üretim firmalarından görüşmeler sonucu elde edilen verilerle işletmelerin I4.0'1 uygulayabilme ve entegrasyon yeteneği için değerlendirmeler gerçekleştirilmiştir. Toplanan veriler; bilgi teknolojileri, araştırma-geliştirme faaliyetleri, müşteri ilişkileri, finansman, kalite yönetimi, planlama, maliyet yönetimi vb. birçok farklı başlık altında analiz edilmiş ve Veri Zarflama Analizi (VZA) kullanılarak detaylı değerlendirmeler yapılması sağlanmıştır.

\section{LITERATÜR TARAMASI}

I4.0 tanıtıldığ 2011 yılından bugüne özellikle üretim işletmelerinde yoğun ilgi görmüş ve çeşitli şekillerde işletmelerin bünyelerine kazandırılmaya çalışılmıştır. Özellikle farklı teknolojik altyapısı ve entegrasyon zorlukları barındıran I4.0 teknolojileri için literatürde farklı çerçeveler çizilmiş ve karşılaşılan problemler tartışılmıştır. I4.0'1n yapı taşlarını oluşturan büyük veri ve analizi, otonom robotlar, simülasyon, yatay ve dikey sistem entegrasyonu, endüstriyel IoT, siber güvenlik, bulut teknolojisi, katmanlı üretim ve artırılmış gerçeklik üzerinde durularak işletmelerin I4.0'a geçmeleri için gerekli önerilerde bulunulmuştur [6]. Buna göre işletmeler önceliklerini belirlemeli ve nitelikli işgücünü yükseltmeli, tedarikçiler teknolojilerden yararlanmalı ve son olarak altyap1 ve eğitim uyarlanmalıdır [6]. Üretim işletmelerinde kullanılan I4.0 teknolojileri (IoT, siber fiziksel sistemler, bulut tabanlı imalat vb.) ile ilgili yaşanan zorluklar için alternatif bir model önermiş, 
yazarlar dokuz farklı boyutta (ürünler, müşteriler, işlemler, teknoloji, strateji, liderlik, yönetişim, kültür, insanlar) I4.0 olgunluğu değerlendirmiştir [7]. Geliştirilen model pratik bir araca dönüştürülerek birkaç şirkette test edilmiş ve bir vaka sunulmuştur. Alınan ilk sonuçlar modelin şeffaf, kullanımının kolay ve gerçek üretim ortamlarında uygulanabilirliğini kanıtlamıştır [7]. Farklı bir çalışmada, ürün yaşam döngüsünün kısalması ve işletmelerde bulunan teknolojinin gereken üretim verimi için yeterli olmadığından yola çıkılarak yeni iş modelleri, şirketlerin rekabeti ve inovasyon boşluğu gibi konular tartışılmıştır [8]. Yazarlar zayıf veri yönetiminin maliyetlerini göz önüne aldığında I4.0'ın sunduğu çözümlerin kapsamlı ve uygulanabilir olduğunu ancak teknolojilere geçişin kapsamlı bir strateji gerektirdiği ve veri entegrasyonu, veri güvenliği, geçiş sırasında olabilecek süreç aksaklıkları, malzeme kayıpları gibi konuların dikkate alınması gerekliliğini vurgulamaktadırlar [8]. Son olarak I4.0'ın vaat ettiği bulut bilişim, katmanlı üretim vb. çözümlerin kullanımı için adım adım geçişin uygun olacağ1 öngörülmüştür [8]. I4.0'1n uygulanabilmesi için üretim operasyonları ve bilgi teknolojisi gibi öncelikli birkaç alan stratejiktir [9]. Bu konuda birkaç kavram ve strateji üzerinde durulmuş ve kapsanmayan alanlar için literatürden seçilen farklı kavram ve stratejiler karşılaştırılmıştır [9]. Elde edilen bulgularda I4.0 ile sektörde sürdürülebilirlik, nitelikli işgücü ve endüstrinin tüm segmentlerinde optimizasyonun sağlanabileceği öngörülmüştür [9]. Norveç'te faaliyet gösteren 4 şirkete yapılan anketler ile I4.0 teknolojilerinin nasıl uygulanabileceği belirlenmeye çalıșılmıştır [10]. Elde edilen bulgular I4.0'in üretim lojistiğinde uygulanabilirliğinin üretim ortamına bağlı olduğunu ve üretim tekrarı az olan şirketlerde malzeme akışının karmaşık olduğu üretim lojistiğinde I4.0 teknolojilerini uygulamada daha az potansiyele sahip olduğunu göstermektedir [10].

Şirket teknoloji seviyeleri I4.0'a geçiş aşamasında önemli bir faktördür [11]. Malezya şirketlerinin teknoloji kullanımları konusunda değerlendirmeler yapmak için borsadaki finansal oranları kullanan yazarlar aynı zamanda şirketlerin verimliliğini maksimize etmek için şirket girdi ve çıtı ağırlıklarının optimum kontrolünü belirlemeye çalışmışlardır [11]. Lingo paket programında VZA modeli ile çözülen modelde incelenen şirketlerin \%44'ünün teknoloji yönünden etkin olduğu görülmüştür [11]. Bir başka çalışmada değişen teknoloji ve iş modellerine karşı işletmelerin adaptasyonu için yazılım sistemleri entegrasyonun öncelikli hale geldiği belirtilmiştir [12]. İşletmelere uygulanan yazılım sistemlerinin entegrasyonlarının iş değerinin tahmini için VZA yöntemi kullanılmış ve işletme entegrasyonunda marjinal faydaların belirlenmesinde VZA yöntemin kullanımı anlatılmaktadır [12]. I4.0'nin son teknoloji incelemesinde, temel tasarım ilkeleri, mimari tasarım tanımlaması, teknoloji eğilimleri ve üreticiler için stratejik bir yol haritası sunulmuştur [13]. Yazar I4.0'1 12 tasarım ilkesi ve 14 teknoloji trendinden oluşan bütüncül bir değer yaratma sistemi olarak tanımlamıştır [13]. I4.0'a geçişin ilk adımı olarak imalat şirketinin atması gereken her adım, zaman çizelgesi ve her adımla ilişkili maliyet ve faydaları tanımlayan ve planlayan kapsamlı bir stratejik yol haritasının geliştirilmesi olarak belirlenmiştir [13]. Dijitalleşme için çalışan 2 küçük şirket, bir orta ölçekli ve 4 büyük ölçekli şirket için öz denetime dayalı bir değerlendirme yöntemi ile dijitalleşmeye hazır olunup olunmadığı tespit edilmeye çalışılmıştır [14]. Ayrıca bir vaka çalışması ile dijitalleşmeye engel olan nedenler, zorluklar ve dijitalleşmeyi kolaylaştırıcıların belirlenmesi amaçlanmıştır [14]. Büyük şirketleri entegrasyon, ortak bir strateji oluşturma, daha yüksek karmaşıklık seviyesi ve farklı hedefler zorlarken veriye dayalı süreçler, tüm şirket türleri için bir boşluk olarak görülmüştür [14]. İmalat sektöründe I4.0 benimsenmesini ölçmek için $\mathrm{AB}$ ülkeleri genelinde I4.0'1 temsil eden faktörlerin varlığı analiz edilmiştir [15]. Analizde AB düzeyinde ülkeler arasında büyük farklılıklar gösteren 5 homojen ülke grubu bulunmuştur. Ayrıca analiz, büyük verilerle başa çıkmak için analitik yeteneklerle birleştirilmiş dijital bir altyapının varlığının, her ülkede I4.0'a hazırlığı gösteren iki boyut olarak ortaya çıktığını kanıtlamıştır [15]. I4.0'in benimsenmesinin teknoloji sağlayıcılar 
açısından sentezlemiş ve Portekiz'de teknoloji kümesinde bulunan 10 şirkette olay araştırılması yapılmıştır [16]. I4.0 teknolojilerinin (siber fiziksel sistemler, bulut bilişim, IoT, vb.) benimsenme konusundaki temel zorlukların üretilen verilerin analizi, yeni teknolojilerin mevcut ekipman ve işgücü ile entegrasyonu ve hesaplama sınırlamaları olduğunu belirlenmiştir [16]. Çalışmada iç kaynakların, ortaklarının ve diğer kümelenme şirketlerinin tamamlayıcı faaliyetleri ve bütünleşik çalışmaları ile şirketin iş modelinde değişiklikler öngörülmüştür [16].

I4.0 teknolojilerinin uygulanması için öngörülen çerçeveler yapılan birçok çalışmada farklı olmaktadır. I4.0 içerisinde tanımlanan ön ve uç teknolojiler için kavramsal bir çerçeve önerilmiş, akıllı üretim, akıllı ürünler, akıllı tedarik zinciri ve akıllı çalışma için IoT, bulut hizmetleri, büyük veri ve analitik temel teknolojileri dikkate alınmıştır [2]. Ele alınan teknolojilerin uygulanması için 92 imalat işletmesinde anket gerçekleştirilmiştir. İncelenen örnekte büyük veri ve analitiğinin kullanımının hala düşük olduğu için I4.0 teknolojilerinin şirketlere uygulanmasının zor olduğu ortaya konmuştur [2]. Doğrudan yabanc1 yatırım barındıran fabrikaların yan kuruluşlarında gelişmiş üretim teknolojilerinin (GÜT) etkisi araştırılmıştır [17]. Macaristan'da bu konu ile ilgili bilgi toplayan yazar, üretim kapasitesinin tüm bileşenlerinin olağanüstü bir şekilde geliştirildiğini tespit etmiş ve GÜT'ün belirli Ar-Ge faaliyetlerini destekleyerek yan kuruluş düzeyindeki Ar-Ge yeteneklerinin yükseltilmesini teşvik ettiği belirlenmiştir [17].

I4.0 teknolojilerinin uygulanma stratejileri farklı üretim teknikleri ile kesişmektedir. $\mathrm{Bu}$ durum uygulanabilirliği etkilemekte ve üretim teknikleri arasındaki uyumun sağlanmasını gerektirmektedir. Yalın üretim ile I4.0' 1 çok farklı stratejiler kullanmasına karşılık bazı ortak noktaların varlığı vurgulanmıştır [18]. Çalışmada yalın üretim prensipleri baz alınarak I4.0 teknolojileri ile ilişkisi ortaya konmuştur. Buna göre tam zamanlı üretim ve Jikoda tekniğinin I4.0 teknolojileri tarafından güçlü bir şekilde desteklendiğini ancak israf ve işgücü kazancı ve ekip çalışması konusunda I4.0 teknolojileri çok az veya hiç destek sağlayamamıştır [18]. Bu nedenle I4.0 teknolojileri tüm yalın tekniklerini destekleyememekte ve yalın tekniklerin bazılarının hala uygulanması gerekliliği doğmaktadır [18]. İmalat şirketlerinin iş süreçlerinde teknolojileri etkinleştiren I4.0 uygulamalarının neler olduğu üzerine detaylı bir literatür araştırması içermektedir. Yazarlar 186 makaleyi analiz ederek üretim çizelgeleme ve kontrolün en sık araştırılan süreç olduğunu görmüşlerdir [19]. Aynı zamanda hizmet sağlama ve döngüsel tedarik zinciri yönetiminde de artan bir eğilim olduğu, uygulamaların geniş bir süreç yelpazesini kapsayan IoT, büyük veri analitiği ve bulut bilişimin kapsamlı birleşik kullanımını, blok zincir teknolojisinin ise çok fazla tartışılmadığı belirlenmiştir [19].

Bir çalışmada, 2008-2018 yılları arasında yayınlanan 35 makale incelenerek sürdürülebilir üretim kavramlarının ve yeni teknolojilerin kullanılmasının I4.0'ın tüm sürdürülebilirlik boyutları üzerinde entegre bir şekilde olumlu etkilere sahip olabileceği belirlenmiştir [20]. I4.0 gündemindeki sürdürülebilir hedeflere ulaşılmasını sağlamak için sürdürülebilir iş modelleri geliştirmek, sürdürülebilir ve döngüsel üretim sistemleri; sürdürülebilir tedarik zincirleri sürdürülebilir ürün tasarımı gibi konularda politika geliştirilmesini öngörmüştür [20]. Akademi ve uygulama alanından 76 uzmanı içeren Delphi tabanlı bir senaryo analizi yapan yazarlar, ortaya çıkan iş modelleri, büyüklük, giriş engelleri, dikey entegrasyon, kira dağılımı ve faaliyetlerin coğrafi konumu açısından en yaygın beklentilerin yanı sıra tartışmalı konuları vurgulamaktadır [21]. Çalışma sonunda talep özellikleri, değer zinciri katılımcıları arasında verilerin şeffaflığ 1 , katmanlı üretimin ve gelişmiş robotiğin olgunluğu ve akıllı ürünlerin yayılması en yaygın beklentiler olarak belirlenmiştir [21].

I4.0 teknolojilerinin imalat sektöründe uygulanmasının önündeki engeller, gelişmiş ve gelişmekte olan ekonomiler bağlamında incelenmiştir [22]. Kaynak kıtlığının yanı sıra 
dijital bir stratejinin olmaması en önemli engel olarak belirlenmiş ve gelişmekte olan ülkelerde Sanayi 4.0 ile ilgili koordineli ulusal politikaların eksikliğinden kaynaklanan ve firmaların I4.0 devrimini tam olarak yaşamalarını engelleyebilecek teknolojik yeniliğin yayılmasındaki zorlukları vurgulanmıştır [22]. I4.0'1n benimsenmesinin 10R (Reddet, Yeniden Düşün, Azalt, Yeniden Kullan, Onar, Yenile, Yeniden Üret, Yeniden Kullan, Geri Dönüştür ve Kurtarma) ile gelişmiş üretim yetenekleri üzerinde ne kadar büyük bir etkiye sahip olduğu ve bunun bir I4.0 dağıtım sisteminin düzenleyici etkisi altında sürdürülebilir kalkınma üzerindeki sonucu incelenmiştir [23].

\section{YÖNTEM}

\subsection{Veri Zarflama Analizi}

İlk olarak 1957'de bütün ekonomiye tek sektörden uygulanması için bir model ortaya atan Farrell bu modelin herhangi bir etkinliğin ölçümünde etkinliğin kendi arasında ayrllabileceğini öne sürmüştür [24]. VZA ise Charnes, Cooper ve Rhodes tarafından 1978'de aynı çeşit mal ve hizmet üretimi yapan karar vericilerin göreli faaliyetlerinin tespit edilmesi için oluşturulan bir yöntemdir [25]. VZA doğrusal programlamanın özel bir uygulamasıdır ve aynı amaçlara sahip işletmelerin verimliliğini göreli bir şekilde ölçmektedir. Birçok uygulama alanı olan VZA başlıca hastaneler, okullar, bankalar, üretim şirketleri, mahkemeler vb. yerlerde uygulanabilmektedir. $\mathrm{Bu}$ yerlerdeki uygulamalarda benzer amaçlı departmanların karşılaştırmaları ile göreceli etkinlik değerleri elde edilmektedir [26].

Veri zarflama analizinin uygulanabilmesi için karar noktalarının seçimi, girdi ve çıktı faktörlerinin seçimi, modelin seçimi, sonuçların yorumlanması adımları gerekmektedir [27]. VZA karşılaştırmalı bir analiz olduğu için doğru karar birimlerin seçilmesi oldukça önemlidir. Bundan dolayı karar noktaları kullandıkları girdiler ve ürettikleri çıktılar yönünden benzer olmalı, tüm karar noktaları için benzer kaynaklar seti olmalı ve tüm karar noktaları benzer çevre koşullarında çalışıyor olmalıdır [28]. Analizde kullanılan çıktılar birimlerin maddi sonuçlarını gösterdiği için karar birimlerinin amaçları yansıtılmalıdır [29].

Kullanıldığı alana ve varsayımlarına göre farklı VZA yöntemleri uygulanabilmektedir. Seçilecek yöntemin belirlenmesinde girdi ve çıtı üzerindeki denetim durumları göz önüne alınmaktadır. Girdiler üzerinde kontrolün az olması halinde çıktı odaklı modelin kullanılması, çıktılar üzerindeki kontrolün az olması halinde girdi odaklı model oluşturulmalıdır. Toplamsal modeller herhangi bir odak olmaması veya karar vericilerin etkinlikleri önemsememesi durumunda kullanılmalıdır [30]. VZA modellerinin çözümlerinde MaxDEA, DEA Solver, EMS ve DEAP gibi paket programlar sıklıkla kullanılmaktadır [27].

\subsection{Charnes-Cooper-Rhodes (CCR) Modeli}

Veri zarflama analizinde $\mathrm{m}$ adet girdi ve $\mathrm{s}$ adet çıktıya sahip olan $\mathrm{n}$ adet karar verme biriminin her biri için, i. karar verme biriminin i. girdi miktarı $\mathrm{X}_{\mathrm{ij}} \geq 0$ ve j'inci karar verme birimi tarafından üretilen r. çıktı miktarı $Y_{\text {rj }}>0$ 'dır.

Girdi yönelimli kesirli VZA modeli [31];

$\begin{array}{ll}\operatorname{Max} \frac{\sum_{r=1}^{s} a_{r} \cdot Y_{r k}}{\sum_{i=1}^{m} b_{i} \cdot X_{i k}} & \mathrm{i}=1, \ldots, \mathrm{m} ; \\ & \mathrm{r}=1, \ldots, \mathrm{s} ; \\ \sum_{\mathrm{r}=1}^{\mathrm{s}} \mathrm{a}_{\mathrm{r}} \cdot \mathrm{Y}_{\mathrm{rj}} & \mathrm{i}=1, \ldots, \mathrm{n} \\ \sum_{\mathrm{i}=1}^{\mathrm{m}} \mathrm{b}_{\mathrm{i}} \cdot \mathrm{X}_{\mathrm{ij}} & \mathrm{r}=1, \ldots, \mathrm{m} ; \\ \mathrm{a}_{\mathrm{r} \geq \varepsilon>0} & \mathrm{j}=1, \ldots, \mathrm{s} ; \\ \mathrm{b}_{\mathrm{i} \geq \varepsilon>0} & \mathrm{r}=1, \ldots, \mathrm{s} \\ & \mathrm{i}=1, \ldots, \mathrm{m}\end{array}$

Modelde;

$a_{r}$ : k karar birimi tarafından r. çıktıya verilen ağırlık,

$b_{i}$ : k karar birimi tarafından i. girdiye verilen ağırlık,

$Y_{r k}:$ k karar birimi tarafından üretilen r. çıktı,

$X_{i k}:$ k karar birimi tarafından kullanılan i. girdi,

$Y_{r j}:$ j. KVB tarafından üretilen r. çıktı, 
$X_{i j}$ : j. KVB tarafından kullanılan i. girdi, $\varepsilon:$ Pozitif çok küçük bir değer,

Max: En büyükleme olarak ifade edilir.

VZA'da $\mathrm{n}$ adet KVB için $\mathrm{n}$ adet model oluşturulur ve KVB'lerin her biri için görece etkinliğin bulunabilmesi için $\mathrm{n}$ tane en iyileme modelinin çözülmesi gerekir. Modellerin amaç fonksiyonu Eşitlik 1'de gösterilmiştir. Bu denklemde $\mathrm{k}$ tane karar verme birimi için toplam ağırlıklandırılmış sanal çıktıların, toplam ağırlıklandırılmış sanal girdilere oranının maksimize edilmesidir. Problemin çözümü içerisinde, her bir karar birimi kendi toplam faktör verimliliğini maksimum yapacak ağırlıkları belirler. Bu ağırlıklar Eşitlik 2'de gösterilmiş ve girdiler için $\mathrm{b}_{1 \mathrm{k}}^{*}, \mathrm{~b}_{2 \mathrm{k}}^{*} \ldots$, $\mathrm{b}_{\mathrm{mk}}^{*}, \quad$ çıktılar için $\mathrm{a}_{1 \mathrm{k}}^{*}, \mathrm{a}_{2 \mathrm{k}}^{*} \ldots, \mathrm{a}_{\mathrm{sk}}^{*}$ şeklinde gösterilmiştir. Eşitlik 3 ve 4 'te bu ağırlıkların pozitif küçük bir değerden daha büyük olması gerekliliği belirtilmiştir. Daha sonra bu ağırlık değerleri kullanılarak optimum etkinlik değeri olan $\theta^{*}$ elde edilir. Model KVB'lerin her biri için hesaplanan bu $\theta^{*}$ oranının 1 değerinin geçmediğini ve en büyük amaç fonksiyon değerinin 1 olabileceğini göstermektedir.

\subsection{Karar Verme Birimlerin Seçimi}

VZA, karar verme birimleri arasında aynı girdileri kullanarak benzer çıtılar üreterek etkinlik analizi yapabilmektedir. Ele alınan karar verme birimleri arasında performans farklılıkları vardır. Kullanılan KVB'ler aynı piyasa şartlarında, aynı amaçlarla aynı veya benzer işler yapmalıdır. KVB seçimlerinde ya da kararlarında iki şeye dikkat edilmelidir. Bunlardan birincisi KVB'ler kullandıkları kaynaklarla ürettikleri çıktılardan sorumlu olarak tanımlanmalıdır. Diğeri, kullanılan KVB sayısı etkinlik sonuçlarının anlamlı çıkabilmesi için yeterli sayıda olmalıdır.

KVB sayısı ile ilgili Norman kullanılan girdi ve çıktı sayısının çokluğuna göre en az 20 KVB'nin gerekliliğini belirtmiştir [32]. Bu çalışmada incelenen 24 KVB Adana üretim işletmelerinden seçilmiş olup işletmeler kâr amacı güden ve benzer çıktılar üreten işletmelerdir.

\subsection{Girdi ve Çıktıların Seçimi}

Girdi ve çıktıların seçimi VZA'nın uygulanabilirliği açısından çok önemlidir. Yapılan çalışmada üretim işletmelerinin yeni endüstri devrimi teknolojileri veya uygulamaları ile ilgili çalışmalarının ne düzeyde oldukları tek çıktı olarak seçilmiş ve bununla ilgili işletmelerdeki yazılımsal, donanımsal ve süreçsel altyapılar girdi olarak seçilmiştir. Özellikle süreçleri belli olmayan, teknoloji/bilgi altyapısı yetersiz olan ve yeterli düzeyde donanıma sahip olmayan işletmelerin I4.0 çalışmaları yapması oldukça zordur. Çalışmada işletmelerin her biriminden dijitalleşme, kaynak ölçümü, kurum kültürü, teknoloji altyapısı vb. konuları ele alan 39 farklı girdi kullanılmıştır.

Modele çok fazla girdi veya çıktı eklendiğinde VZA'da etkin veya etkin olmayan birimlerin belirlenmesi zorlaşmaktadır. Aynı zamanda çalışma için veri toplamak zorlaşmaktadır. Tüm bu nedenlerden dolayı çalışmada girdi ve çıktı sayıları belirlenirken eşitlik (5) dikkate alınmıştır. Kullanılan bu eşitlik ile girdi ve çıktı sayısının artırılması KVB sayısına bağlanmıştır.

$\mathrm{N}>(\mathrm{m}+\mathrm{s}) / 2$

\section{N: KVB sayısı, m: Girdi sayısı, s: Çıktı sayısı}

Çizelge 1'de kullanılan 39 farklı girdi ve 1 çıktı gösterilmektedir. Belirlenen girdiler Adana bölgesinde faaliyet gösteren 24 firmadan elde edilmiştir. $\mathrm{Bu}$ girdiler, işletmelerin tüm fonksiyonlarından çalışma amacına yönelik verilerden oluşmaktadır. Dijital dönüşüm süreci boyunca işletmelerin I4.0 teknoloji ve uygulamalarına ne kadar uyum sağladıklarının öğrenilmesi amaciyla Kurumsal Kaynak Planlaması (KKP) süreçleri, kalite, teknoloji altyapısı ve insan kaynağı konuları özellikle ele alınmıştır. Bu konuların değerlendirilmesi için Likert ölçeği ile 1 ile 5 arasındaki puanlarla değerlendirme yapılmıştır. Seçilen bu girdilerin sonucunda tek bir çıktı olan vizyonel I4.0 çalışma düzeyleri belirlenmeye çalışmıştır. 
Çizelge 1. Çalışmada kullanılan girdi ve çıktılar

\begin{tabular}{|l|l|}
\hline INPT1 & Ar-Ge kaynağı \\
\hline INPT2 & Ar-Ge çalışan sayısı \\
\hline INPT3 & İnovasyon becerisi \\
\hline INPT4 & Teknolojik altyapı \\
\hline INPT5 & Finansal araçlarla iletişim \\
\hline INPT6 & Envanterin İzlenebilirliği \\
\hline INPT7 & KKP raporlama \\
\hline INPT8 & Bilgi güvenliği \\
\hline INPT9 & Müşteri İlişkileri Yönetimi (MiY) kullanımı \\
\hline INPT10 & Bilgi Teknolojileri (BT) güncelliği \\
\hline INPT11 & KKP finansal modüllerini kullanabilme \\
\hline INPT12 & KKP muhasebe modüllerini kullanabilme \\
\hline INPT13 & KKP satış ve satın alma modüllerini kullanabilme \\
\hline INPT14 & KKP üretim planlama modülü kullanabilme \\
\hline INPT15 & $\begin{array}{l}\text { KKP operasyonlar yönetimi modüllerini } \\
\text { kullanabilme }\end{array}$ \\
\hline INPT16 & İnternet altyapısı \\
\hline INPT17 & Tedarik zinciri yönetimi yazılımı kullanımı \\
\hline INPT18 & Barkod sistemi kullanımı \\
\hline INPT19 & Sipariş sistem verimliliği \\
\hline INPT20 & Kurum web sayfası kullanımı \\
\hline INPT21 & Sürekli eğitim \\
\hline INPT22 & Süreç iyileştirme \\
\hline INPT23 & KKP malzeme yönetim modüllerini kullanabilme \\
\hline INPT24 & Malzeme ihtiyaç planlaması çalışmaları \\
\hline INPT25 & Dijital belge yönetim sistemleri \\
\hline INPT26 & Donanım altyapapıs yeterliliği \\
\hline INPT27 & Tedarik zinciri yönetimi \\
\hline INPT28 & Yalın üretim düzeyi \\
\hline & \\
\hline
\end{tabular}

\begin{tabular}{|l|l|}
\hline INPT29 & Satın alma ve üretim iletişimi \\
\hline INPT30 & Kariyer yönetim sistemi \\
\hline INPT31 & Tedarik zinciri optimizasyonu çalışmaları \\
\hline INPT32 & Verimlilik izleme \\
\hline INPT33 & Makine verimliliği ölçülebilme düzeyi \\
\hline INPT34 & Teknolojiye yapıllan yatırım düzeyi \\
\hline INPT35 & İş süreçlerinin analiz çalışmaları \\
\hline INPT36 & Eğitim planlaması \\
\hline INPT37 & Kurum teknoloji gelişimininin takip edilmesi \\
\hline INPT38 & Kariyer yönetim sistemi \\
\hline INPT39 & Performans yönetim sistemi \\
\hline OUTPT1 & Vizyonel Endüstri 4.0 çalışma düzeyi \\
\hline
\end{tabular}

\section{BULGULAR}

Çalışmada incelenen işletmelerin birbirine göre göreceli etkinlikleri VZA yöntemi kullanılarak belirlenmiştir. VZA yöntemi bir paket programı olan MaxDEA 8 programı yardımıyla uygulanmıştır. Kullanılan girdi ve çıktılar tüm işletmelerde elde edilebilen, ölçülebilen ve karşılaştırılabilen verilerden oluşmuştur. Yapılan analizlerin sonucu Şekil 1'de gösterilmiş ve yapilan incelemeler sonucu KVB22 0.556 ile etkinlik değeri en düşük olan işletme olurken birden fazla işletme için etkinlik değerinin üst sınırı olan 1 değeri elde edilmiştir.

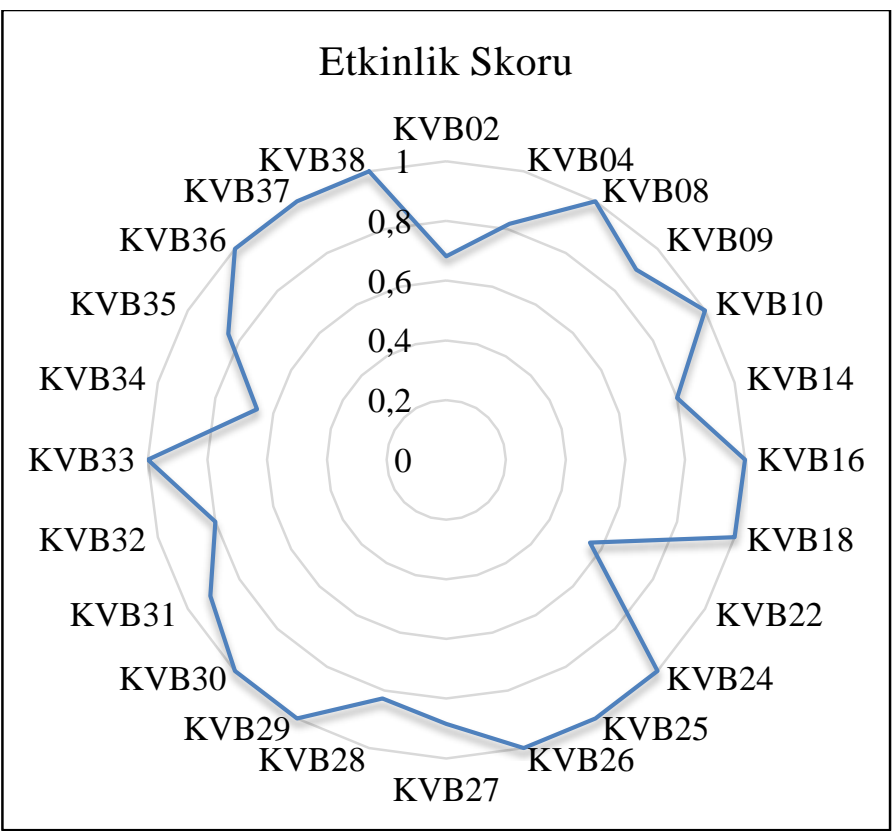

Şekil 1. KVB'lere ait etkinlik skorları 
Çizelge 2'de KVB'lere ait performanslar ve sıralamalar verilmiştir. Buna göre 24 işletmenin 13 tanesi görece etkin değerlere sahipken 11 işletme ise görece etkin olmadığı görülmüştür.

Çizelge 2. KVB'lerin performans ve sıraları

\begin{tabular}{|c|c|c|}
\hline Karar verme birimi & Performans & S1ra \\
\hline KVB02 & Etkin değil & 22 \\
\hline KVB04 & Etkin değil & 19 \\
\hline KVB08 & Etkin & 1 \\
\hline KVB10 & Etkin değil & 15 \\
\hline KVB14 & Etkin & 1 \\
\hline KVB16 & Etkin değil & 20 \\
\hline KVB18 & Etkin & 1 \\
\hline KVB22 & Etkin değil & 1 \\
\hline KVB24 & Etkin & 1 \\
\hline KVB25 & Etkin & 1 \\
\hline KVB26 & Etkin & 1 \\
\hline KVB27 & Etkin değil & 16 \\
\hline KVB28 & Etkin değil & 18 \\
\hline KVB29 & Etkin & 1 \\
\hline KVB30 & Etkin & 1 \\
\hline KVB31 & Etkin değil & 14 \\
\hline KVB32 & Etkin değil & 21 \\
\hline KVB33 & Etkin & 1 \\
\hline KVB34 & Etkin değil & 23 \\
\hline KVB35 & Etkin değil & 17 \\
\hline KVB36 & Etkin & 1 \\
\hline KVB37 & Etkin & 1 \\
\hline KVB38 & Etkin & 1 \\
\hline
\end{tabular}

İşletmelerin birbirine göre göreceli olarak elde edilen etkinlik değerleri incelendiğinde etkin olarak elde edilen 13 işletmenin girdi ve çıktı değerlerinin ortalaması işletmeler arasındaki kıyaslama için fikir oluşturmaktadır. Bu ortalama değerlerinin büyük bir çoğunluğuna göre üstünlük sağlayan işletmeler analiz sonucunda etkin olarak bulunmuştur. Çizelge 3'te görülen ortalamalar etkin olan işletmelere ait girdi ve çıktı ortalamalarını göstermektedir. Buna göre bir işletmenin etkin olabilmesi için envanter izlenebilirliği, dijital belge yönetim sistemleri ve vizyonel I4.0 çalışama düzeylerinin yaklaşık puanı 4'ten fazla olmalıdir. Ancak bu ortalamaların yalnız birine veya birkaçına bakarak işletmelerin etkinliklerini değerlendirmek her zaman doğru sonuçları vermeyebilir. Genel bir çerçevede bir işletme etkinlik değerini artırmak için bu puanları baz alarak geliştirmesi gereken noktaları saptayabilir.

Çizelge 3. Etkin KVB'lerin girdi ve çıtı ortalamaları

\begin{tabular}{|c|c|c|c|}
\hline $\begin{array}{c}\text { Girdi/ } \\
\text { Ç1kt1 }\end{array}$ & $\begin{array}{c}\text { Etkin } \\
\text { işletmelerin } \\
\text { toplam } \\
\text { değerlendirme } \\
\text { puanları }\end{array}$ & $\begin{array}{c}\text { Etkin } \\
\text { işletme } \\
\text { say1s1 }\end{array}$ & $\begin{array}{c}\text { Ortalama } \\
\text { etkinlik } \\
\text { değeri }\end{array}$ \\
\hline INPT1 & 30 & 13 & 2,308 \\
\hline INPT2 & 26 & 13 & 2,000 \\
\hline INPT3 & 41 & 13 & 3,154 \\
\hline INPT4 & 45 & 13 & 3,462 \\
\hline INPT5 & 46 & 13 & 3,538 \\
\hline INPT6 & 53 & 13 & 4,077 \\
\hline INPT7 & 32 & 13 & 2,462 \\
\hline INPT8 & 40 & 13 & 3,077 \\
\hline INPT9 & 21 & 13 & 1,615 \\
\hline INPT10 & 40 & 13 & 3,077 \\
\hline INPT11 & 28 & 13 & 2,154 \\
\hline INPT12 & 39 & 13 & 3,000 \\
\hline INPT13 & 29 & 13 & 2,231 \\
\hline INPT14 & 30 & 13 & 2,308 \\
\hline INPT15 & 32 & 13 & 2,462 \\
\hline INPT16 & 45 & 13 & 3,462 \\
\hline INPT17 & 17 & 13 & 1,308 \\
\hline INPT18 & 41 & 13 & 3,154 \\
\hline INPT19 & 50 & 13 & 3,846 \\
\hline INPT20 & 38 & 13 & 2,923 \\
\hline INPT21 & 45 & 13 & 3,462 \\
\hline INPT22 & 43 & 13 & 3,308 \\
\hline INPT23 & 37 & 13 & 2,846 \\
\hline INPT24 & 37 & 13 & 2,846 \\
\hline INPT25 & 55 & 13 & 4,231 \\
\hline INPT26 & 48 & 13 & 3,692 \\
\hline INPT27 & 45 & 13 & 3,462 \\
\hline INPT28 & 37 & 13 & 2,846 \\
\hline INPT29 & 54 & 13 & 4,154 \\
\hline INPT30 & 46 & 13 & 3,538 \\
\hline INPT31 & 45 & 13 & 3,462 \\
\hline INPT32 & 51 & 13 & 3,923 \\
\hline INPT33 & 47 & 13 & 3,615 \\
\hline INPT34 & 46 & 13 & 3,538 \\
\hline INPT35 & 50 & 13 & 3,846 \\
\hline INPT36 & 42 & 13 & 3,231 \\
\hline INPT37 & 29 & 13 & 2,231 \\
\hline INPT38 & 47 & 13,615 \\
\hline INPT39 & 31 & 2,385 \\
\hline OUTPT1 & 53 & 4,077 \\
\hline
\end{tabular}


İşletmelerin ortalama etkinlik değerleri incelendiğinde 0,903 gibi 1'e yakın olan bir değer olduğu görülmektedir. İşletmelerin etkinlik değerleri arasında değişim ise 0,13 gibi çok fazla değişken olmayan bir değerdir. Çizelge 4'te görüldüğü gibi etkin olmayan işletmeler kendi aralarında incelendiğinde değişkenliğin yine az olduğu görülebilmektedir. Bu sonuçlar, işletmeler arasında çok fazla bir etkinlik farkı olmadığını ortaya koymaktadır. Ancak KVB22 (0,566), KVB34 (0,656), KVB02 (0,681) gibi işletmelerin değişkenliğin çok olmadığı bu işletmeler arasında etkinlik değerinin oldukça düşük olduğu söylenebilir.

Çizelge 4. KVB'lerin etkinlik istatistikleri

\begin{tabular}{|l|c|}
\hline Toplam işletme sayısı & 24 \\
\hline Etkin işletme sayısı & 13 \\
\hline Ortalama etkinlik skoru & 0,903 \\
\hline En düşük etkinlik & 0,556 \\
\hline En düşük etkinliğe sahip işletme & KVB22 \\
\hline Tüm işletmelerin std. sapması & 0,130 \\
\hline $\begin{array}{l}\text { Etkin olmayan işletmelerin etkinlik } \\
\text { ortalaması }\end{array}$ & 0,789 \\
\hline Etkin olmayan işletmelerin std. sapması & 0,112 \\
\hline
\end{tabular}

\section{SONUÇLAR VE TARTIŞMA}

Günümüz işletmeleri ileri teknoloji, hızlı üretim ve teslimat, kaliteli ürün, satış sonrası hizmet imkanları gibi çeşitli niteliklere sahip olmak zorundadır. Yeni endüstri devrimi ile bu niteliklerin yeterli olmayacağı kitlesel ve siparişe dayalı üretimin kişiye özel üretime dönmesi beklenmektedir. Bütün bu beklentiler imalat işletmelerini yeni endüstri devrimine geçişe zorlamaktadır. Ancak yeni endüstri devriminin geçişi ileri teknoloji, dijital süreçler, yeterli donanım ve yazılım alt yapısı vb. birçok ön şartın gerçekleşmesini de zorunlu kılmaktadır. $\mathrm{Bu}$ çalışmada bir imalat işletmesinin I4.0 entegrasyonunun değerlendirmesi için 24 işletmeye 40 sorunun yöneltilmesiyle elde edilen veriler kullanılmıştır. $\mathrm{Bu}$ verilerin değerlendirmesinde VZA yöntemi kullanılmıştır. Kullanılan verilerin 39'u girdi değişkeni olarak seçilmiş ve sonucunda bir tane çıktı değişkeni incelenmiştir.

Yapılan çalışma sonucunda 24 işletmenin 13 tanesi etkin çıkarken 11 tanesi ise etkin olarak bulunmamıştır. Yapılan analiz sonucunda her girdi ve çıktı için ortalama etkinlik değeri hesaplanmış ve etkin olmayan işletmeler için bir hedef değer oluşturulmuştur. Ortalama etkinlik skoruna bakıldığında 0,903'lük yüksek bir değer elde edilmiş ancak en düşük etkinlik değeri 0,556 olarak bulunmuştur. Ayrıca tüm işletmeler ve etkin olmayan işletmeler ayrı ayrı incelenerek değişkenliği incelenmiştir. Buna göre her iki grubun da değişkenliği çok fazla olmamakla beraber etkin olmayan işletmelerin değişkenliği daha azdır. $\mathrm{Bu}$ durum, işletmeler arasındaki etkinlik skor farkının çok fazla olmadığı anlamına gelmektedir. Yapılan çalışmanın, incelenen işletmeler bazında I4.0 geçişi için değerlendirmelerde bulunması ve etkinlik değerleri ile bu işletmelerin odaklanması gereken yerleri işaret etmesi açısından önemli olduğu düşünülmektedir. Bunun yanında çalışmada I4.0 için gerekli teknolojiler ve işletme içerisinde bu teknolojilere entegrasyonu sağlamak için gerekli olan girdilerin belirlenmesi çalışmayı önemli kılan bir başka noktadır.

Gelecek çalışmalar için farklı değerlendirme kriterlerinin ele alınması mümkündür. Çalışma daha farklı firmalarla yapılabilir ve gelişmelerin izlenmesi için bir Endüstri 4.0 entegrasyonu ölçeği oluşturularak zaman içerisindeki değişimlerin ele alınacağı bir sistem oluşturulabilir. Son olarak farklı karar verme yaklaşımlarının entegrasyonu ve bulanık mantık gibi yaklaşımlar da denenebilir. VZA ile işletmeler arasında bir etkinlik sıralaması k1smen yap1labilmektedir. Etkin olmayan işletmelerin etkinlik skorları kullanılarak bir sıralama yapılabilirken etkin olan işletmelerin tamamının değeri 1 olduğu için sıralanması mümkün olmamaktadır. $\mathrm{Bu}$ nedenle farklı yaklaşımlar ve çok kriterli karar verme yöntemleri işletmeler arasında bir sıra yapılmasına imkan verebilir. 


\section{6. ÇIKAR ÇATIŞMASI}

Bu makalede yazarlar tarafından herhangi bir çıkar çatışması oluşturacak durum gözlenmemiştir. Bundan dolayı çıkar çatışması bölümüne yer verilmemiştir.

\section{KAYNAKLAR}

1. Lee, J., Bagheri, B., Kao, H.A., 2015. A Cyberphysical Systems Architecture for Industry 4.0Based Manufacturing Systems. Manufacturing Letters, 3, 18-23.

2. Frank, A.G., Dalenogare, L.S., Ayala, N.F., 2019. Industry 4.0 Technologies: Implementation Patterns in Manufacturing Companies. International Journal of Production Economics, 210, 15-26.

3. Wan, J., Tang, S., Li, D., Wang, S., Liu, C., Abbas, H., Vasilakos, A.V., 2017. A Manufacturing Big Data Solution for Active Preventive Maintenance. IEEE Transactions on Industrial Informatics, 13(4), 2039-2047.

4. McFarlane, D., Sarma, S., Chirn, J.L., Wong, C., Ashton, K., 2003. Auto ID Systems and Intelligent Manufacturing Control. Engineering Applications of Artificial Intelligence, 16(4), 365-376.

5. Zhong, R.Y., Xu, X., Klotz, E., Newman, S.T., 2017. Intelligent Manufacturing in the Context of Industry 4.0: A Review. Engineering, 3(5), 616-630.

6. Rüßmann, M., Lorenz, M., Gerbert, P., Waldner, M., Justus, J., Engel, P., Harnisch, M., 2015. Industry 4.0: The Future of Productivity and Growth in Manufacturing Industries. Boston Consulting Group, 9(1), 54-89.

7. Schumacher, A., Erol, S., Sihn, W., 2016. A Maturity Model for Assessing Industry 4.0 Readiness and Maturity of Manufacturing Enterprises, Procedia Cirp, 52, 161-166.

8. Khan, A., Turowski, K., 2016. A Survey of Current Challenges in Manufacturing Industry and Preparation for Industry 4.0. In Proceedings of the First International Scientific Conference "Intelligent Information
Technologies for Industry" (IITI'16), Springer, Cham, 15-26.

9. Crnjac, M., Veža, I., Banduka, N., 2017. From Concept to the Introduction of Industry 4.0. International Journal of Industrial Engineering and Management, 8(1), 21-30.

10. Strandhagen, J.W., Alfnes, E., Strandhagen, J.O., Vallandingham, L.R., 2017. The Fit of Industry 4.0 Applications in Manufacturing Logistics: A Multiple Case Study. Advances in Manufacturing, 5(4), 344-358.

11. Siew, L.W., Fai, L.K., Hoe, L.W., 2018. An Optimal Control on the Efficiency of Technology Companies in Malaysia with Data Envelopment Analysis Model. Journal of Telecommunication. Electronic and Computer Engineering (JTEC), 10(1), 107-111.

12. Fazlollahi, A., Franke, U., 2018. Measuring the Impact of Enterprise Integration on Firm Performance Using Data Envelopment Analysis. International Journal of Production Economics, 200, 119-129.

13. Ghobakhloo, M., 2018. The Future of Manufacturing Industry: A Strategic Roadmap Toward Industry 4.0. Journal of Manufacturing Technology Management.

14. Machado, C.G., Winroth, M., Carlsson, D., Almström, P., Centerholt, V., Hallin, M., 2019. Industry 4.0 Readiness in Manufacturing Companies: Challenges and Enablers Towards Increased Digitalization. Procedia Cirp, 81, 1113-1118.

15. Castelo-Branco, I., Cruz-Jesus, F., Oliveira, T., 2019. Assessing Industry 4.0 Readiness in Manufacturing: Evidence for the European Union. Computers in Industry, 107, 22-32.

16. Dalmarco, G., Ramalho, F.R., Barros, A.C., Soares, A.L., 2019. Providing Industry 4.0 Technologies: The Case of a Production Technology Cluster. The Journal of High Technology Management Research, 30(2), 100355.

17. Szalavetz, A., 2019. Industry 4.0 and Capability Development in Manufacturing Subsidiaries. Technological Forecasting and Social Change, 145, 384-395.

18. Rosin, F., Forget, P., Lamouri, S., Pellerin, R., 2020. Impacts of Industry 4.0 Technologies on 
Lean Principles. International Journal of Production Research, 58(6), 1644-1661.

19.Zheng, T., Ardolino, M., Bacchetti, A., Perona, M., 2020. The Applications of Industry 4.0 Technologies in Manufacturing Context: A Systematic Literature Review. International Journal of Production Research, 1-33.

20. Machado, C.G., Winroth, M.P., Ribeiro da Silva, E.H.D., 2020. Sustainable Manufacturing in Industry 4.0: an Emerging Research Agenda. International Journal of Production Research, 58(5), 1462-1484.

21. Culot, G., Orzes, G., Sartor, M., Nassimbeni, G., 2020. The Future of Manufacturing: a Delphi-based Scenario Analysis on Industry 4.0. Technological Forecasting and Social Change, 157, 120092

22. Raj, A., Dwivedi, G., Sharma, A., de Sousa Jabbour, A.B.L., Rajak, S., 2020. Barriers to the Adoption of Industry 4.0 Technologies in the Manufacturing Sector: An Inter-country Comparative Perspective. International Journal of Production Economics, 224, 107546.

23. Bag, S., Gupta, S., Kumar, S., 2021. Industry 4.0 Adoption and 10R Advance Manufacturing Capabilities for Sustainable Development. International Journal of Production Economics, 231, 107844.

24. Eken, M.H., Kale, S., 2011. Measuring Bank Branch Performance Using Data Envelopment Analysis: The Case of Turkish Bank Branches. African Journal of Business Management, 5(3), 889-901.

25. Banker, R.D., 1992. Estimation of Returns to Scale Using Data Envolopment Analysis. European Journal of Operational Research, Vol. 62.

26. Timor, M., 2001. Yöneylem Araştırması ve İşletmecilik Uygulamaları. İstanbul Üniversitesi İşletme Fakültesi Yayınları, İstanbul.

27. Dinçer, E., 2008. Veri Zarflama Analizi'nde Malmquist Endeksiyle Toplam Faktör Verimliliği Değişiminin İncelenmesi ve İMKB Üzerine Bir Uygulama. Marmara Üniversitesi İ̈BF Dergisi, 15(2), 825-846.

28. Kaya, Y., Doğan E., 2005. Dezenflasyon Sürecinde Türk Bankacılı Sektöründe
Etkinliğin Gelişimi. BDDK, ARD Çalışma Raporlar1.

29. Aslankaraoğlu, N., 2006. Veri Zarflama Analizi ve Temel Bileşenler Analizi ile AB Ülkelerinin Sıralaması. Gazi Üniversitesi, Fen Bilimleri Enstitüsü, Yüksek Lisans Tezi, Ankara, 142.

30. Çavmak, Ş., 2017. Sağlık Hizmetlerinde Veri Zarflama Analizi ve Modelleri. Sağlık Yönetimi Dergisi, 1(1), 35-47.

31. Özden, Ü., 2008. Veri Zarflama Analizi (VZA) ile Türkiye'deki Vakıf Üniversitelerinin Etkinliğinin Ölçülmesi. İstanbul Üniversitesi İşletme Fakültesi Dergisi, 37(2), 167-185.

32. Norman, M., Stoker, B., 1991. Data Envelopment Analysis: The Assessment of Performance, John Wiley \& Sons, Inc. 
